\title{
Building skin and energy efficiency in a hot climate with particular reference to Dubai, UAE
}

\author{
M. A. Haggag \\ UAE University, United Arab Emirates
}

\begin{abstract}
The city of Dubai, which is the second largest of seven emirates of the United Arab Emirates, has been significantly shaped by various modern ideologies. It has become one of the wealthiest and most modern cities anywhere in the world, boasting the highest skyline in the Middle East. Despite the fact that Dubai is one of the hottest cities in the Gulf region, its modern architecture is characterized by transparent buildings. Most of the new buildings adopt the concept of a fullyglazed façade despite a lack of knowledge about the energy impact. Such a concept comes, in fact, with increased operational costs due to the higher solar gain. It is important for architects and engineers to understand the behaviour of the buildings they design if environmental performance and comfort are to be maximized. To achieve appropriate conditions, technical installations are much utilised to compensate for shortcomings in the concept of the building skin.

Based on the climatic conditions of Dubai, the paper attempts to increase energy efficiency by identifying the optimal parameters for building skins. Attention is given to the use of double skin façade systems, since these allow natural ventilation, provide a degree of sound insulation, provide a reduction in energy consumption, and increase occupant comfort. In this context, various issues will be considered: urban transformation patterns of Dubai; the performance of the building skin; the strategies of double skin façade; and lessons of experience.

Keywords: building skin, energy efficiency, double skin facades, Dubai.
\end{abstract}




\section{Introduction}

Hot and humid climates, such as those in Dubai, generate unique challenges to architects and engineers seeking energy efficient building designs. In modern building practice, the use of transparent facades has gained increasing popularity throughout the world. The occupants often like the idea of a better view and a more pleasant indoor environment. Glazed facade strategy usually comes with a high operational cost. Designers can reduce building skin related energy losses by reducing air leakage through the external skin, using high performance windows, increasing insulation levels, and minimizing thermal bridging. In terms of energy efficiency, the use of double skin facades (DSFs) has also gained increasing popularity.

Using DSFs, the transparent building concept can be adopted and energy consumption minimized. This concept can increase comfort, reduce operating costs, and reduce overall energy use and negative environmental impacts (Selkowitz [1]). Despite these valuable advantages, there is a little experience of using DSF technique, not only in Dubai but also in the Gulf cities. One reason, as pointed out by Oesterle et al [2], is that clients and developers are concerned about the additional costs associated with multi-layered facades and need to be convinced of the advantages of this type of construction.

\section{Dubai and its urban transformation pattern}

The rapid transformation of Dubai and its wider urban region during the last few decades demands greater critical analysis than it has so far attracted. Three issues in particular motivate this profile. First, the city of Dubai is an international trading centre; a "global city". Second is the dramatic nature of the development of the city over several decades, in terms of population increase, spatial expansion and economic growth, most spectacularly in the development of the centre of Dubai, "Sheikh Zayed Road" (see figure 1). Third is Dubai's emerging status as an urban region.

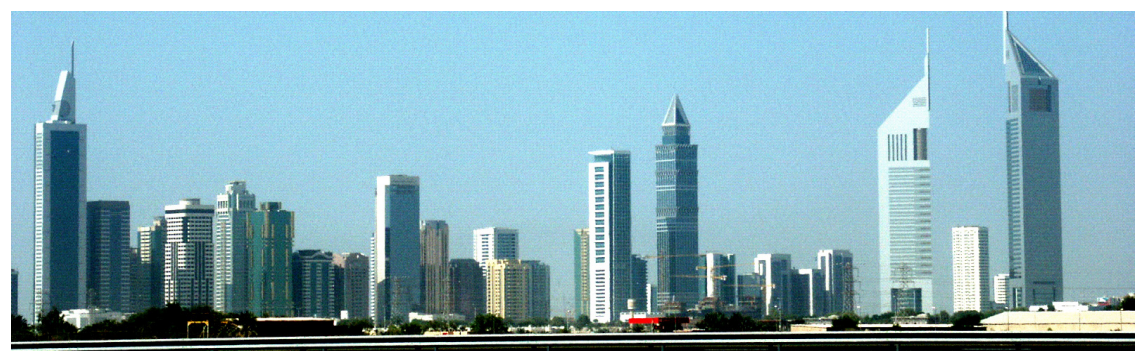

Figure 1: The central area of Dubai characterized by skyscrapers and glazed facades.

Urban development in Dubai can be divided into traditional, conventional and modern processes. The traditional process reflects architectural and planning ideologies of the pre-modern era (characterized by courtyard, wind-towers, small 
windows, low-rise buildings). The modern process was established during the second half of the 19th century, with fast urban development following the discovery of oil. Dubai became one of the most modern cities in the world, boasting the highest glass towers in the Middle East, including the second tallest twin towers in the world "Emirates Twin Towers" (figure 2(a)), the world's tallest hotel "Burj Al-Arab", and the world's tallest tower "Burj Dubai", still under construction (figure 2(b)). With its modern architecture, Dubai will be one of the world's leading skyscraper cities by 2009, with twelve buildings taller than 305 meters including, by then, Burj Dubai with glass facades and a height of 808 meters and (figure 2(c)) (Eaamar [3]).

(a)

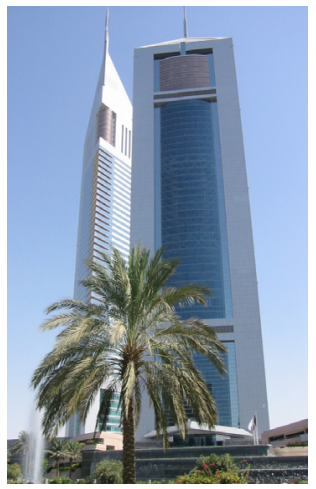

(b)

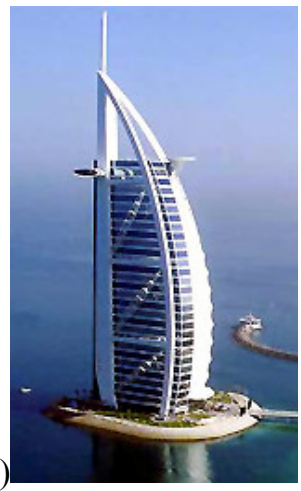

(c) $[3]$

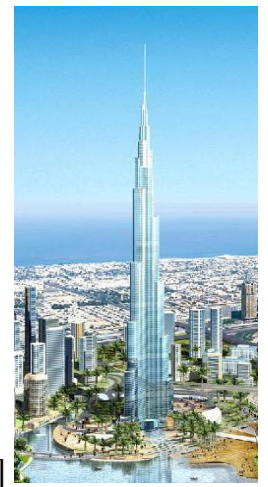

Figure 2: (a) Emirates Twin Towers (350 m office tower, $305 \mathrm{~m}$ hotel), Dubai (b) Burj Al-Arab hotel (321 m), Dubai. (c) Burj Dubai, the world's tallest tower (808m).

Despite the fact that Dubai is one of the hottest cities in the Gulf region, the use of glazed facades has gained increasing popularity throughout the city. This concept comes with increased operational costs due to the higher solar gain. There are many alternatives to conquer such problems. In many parts of the world, the double skin façade (DSF) has been used to overcome the major disadvantages of transparent facades, since it can provide about 30 per cent reduction in energy consumption, provide natural ventilation, and noise reduction (Glicksman et al [4]). In summer, DSF strategy can reduce heat gain and cooling loads while allowing in daylight and natural ventilation. Moreover, it can reduce heat loss in winter while still capturing solar gain. Despite its practicality for hot arid zones, there is little experience of using DSF systems in the Gulf region. This paper argues that there is a great energy-saving impact in using a single-skin glazed façade. It is then interesting to make a further hypothesis that DSF strategy would also be a solution to the energy problem for the fully glazed buildings of Dubai.

\section{Climatic conditions in Dubai}

Dubai with its hot climate is situated 25 degrees north and 55 degrees east, within a sub-region of the northern desert belt. It is characterized by scarce 
rainfall and high levels for temperature, humidity, and sunshine. Summer sunshine averages 11 hours a day, falling to about 8 hours a day in winter. In summer (May to September), the weather is very hot and humid most of the time with daytime temperatures ranging from $35^{\circ} \mathrm{C}$ to $49^{\circ} \mathrm{C}$. During the winter (December to February), the daytime temperatures range from $25^{\circ} \mathrm{C}$ to $35^{\circ} \mathrm{C}$, and sometimes falling to as low as $9^{\circ} \mathrm{C}$ at night. Rainfall is infrequent and happens mainly in winter, with an annual average rainfall of $7 \mathrm{~cm} \mathrm{[5].}$

\section{Building skin and its performance}

The building skin, which separates the interior spaces from the outdoor environment, is an important concept for energy efficiency. All components of the building skin need to work together to regulate the indoor environment. Building skin is considered a selective pathway for a building to work with the climate, responding to heating, cooling, ventilation, and natural lighting needs. It determines the physical processes and plays a dominant role on the overall energy performance of a building. It controls heat transfer, solar radiation, and airflow. It must balance requirements for ventilation and daylight while providing thermal protection appropriate to the climatic conditions (Reid [6]).

Skin design is a major factor in determining the amount of energy used in buildings. Architects and engineers should integrate design of the building skin with other design aspects including material selection, daylight, heating, ventilation, and air-conditioning. Building function is the second important factor in skin design. If the activity and equipment inside the building generate a significant amount of heat, the thermal loads may be primarily internal rather than external. This affects the rate at which a building gains or loses heat. Building forms, volume, and orientation also have significant impacts upon the efficiency of the building skin. Openings are also critical issue. The opening form, size and location vary depending upon the role they play in the building skin. Glazing systems have a great impact on energy efficiency. Appropriate glazing choices are varied, depending on the type of building skin, the use of the building, and the glazing placement on the facade. In a hot climate, the main strategy is to control heat gain by keeping solar energy from entering the indoor space while allowing reasonable visible light transmittance for views and daylight. In cold climates, the strategy is to reduce heat loss to the outdoors and allow desirable solar radiation to enter (Straube and Straaten [7]).

Construction details also play an important role in designing building skin. Appropriate detailing systems, including choice and placement of insulation material, are essential to guarantee the required level of thermal performance, which has to do with reducing heat transmission. The transmission can occur in three ways: conduction, convection, and radiation. Conduction is where heat passes through a building skin. The conductance of particular building materials or construction elements is the amount of heat that will be conducted through a unit area in unit time for unit temperature differences between the faces of building skin (thermal transmission coefficient U-value); the lower the U-value, the better the insulation. In convection process, air currents collect heat from 
warmer surfaces and impart it to cooler ones. Radiation involves energy transfer by electromagnetic waves (Reid [6]).

\section{The construction of the DSF}

DSF is a system in which two or three layers of glazing are separated by a significant amount of air space. In most cases, the airflow through the glazing cavity is driven by natural flow aided by wind pressure differences or by mechanical fans (Straube and Straaten [7]). Three elements are included: the skin construction, the transparency of the bounding surfaces, and the cavity airflow.

As described by Oesterle et al, there are several construction types of DSFs. The most popular are the box-window system, the shaft-box façade, corridor facades, and the multi-story façade (Oesterle et al [2]). The box-window type has a single-glazed external skin, contains openings to ventilate the cavity and indoor spaces. An additional mechanical system could be supplied to achieve the high level of thermal performance. The cavity between the two skins is divided horizontally and vertically, according to the construction modules and the floor height. This system is suitable where the level of external noise is high and where privacy between rooms is needed.

The shaft-box system is similar to the box-window with a continuance vertical shaft that extends over multiple storeys. The airflow, which increases thermal performance level, is directed through openings located in the external skin. This concept is suitable where high levels of sound insulation are required. It is not recommended for tall buildings, since the height of the stacks is limited (Oesterle et al [2]). The corridor façade system is different from the above two systems. The cavity between the two skins is separated horizontally by floor divisions at the level of each floor. The air intake and extract openings are situated within the external layer in staggered form to create an efficient airflow between the floors. This system is suitable where there is a need for acoustical treatment, fire protection, or for natural ventilation. In the multi-storey façade system, the cavity space is adjoined vertically and horizontally without any intermediate divisions. Openings are situated near the ground floor and others near the final roof to ventilate the cavity. The airflow comes from the bottom of the façade through a motorized damper to adjust the ventilation rate. This could also be achieved by controlling the area of openings (Oesterle et al [2]). The construction of multi-story façades is commonly used where the level of external noise is high, a glazed façade without openings is required, and where it is possible to use a mechanical form of ventilation.

\section{The performance of the DSF}

Most building designers believe that the use of DSFs can provide better natural ventilation and thermal insulation, reduce cooling loads and energy consumption, facilitate daylight, and increase noise control. 


\subsection{Natural ventilation and thermal insulation}

Natural ventilation, thermal insulation, and DSF can be designed in an integrated manner. Natural ventilation might be used in conjunction with artificial cooling by careful design (Straube and Straaten [7]). The intermediate space between the two skins protects the inner spaces from wind and helps to control comfort. This could be achieved by using protected, operable, screened and sound baffled openings situated in the inner skin.

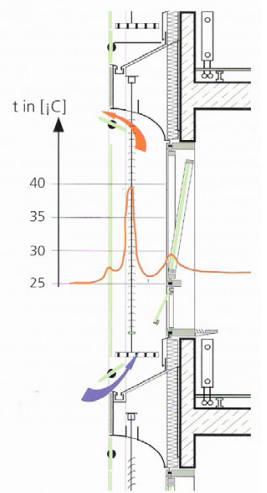

Figure 3: Temperature curve around shading devices in DSF. Source: Oesterle et al [2].

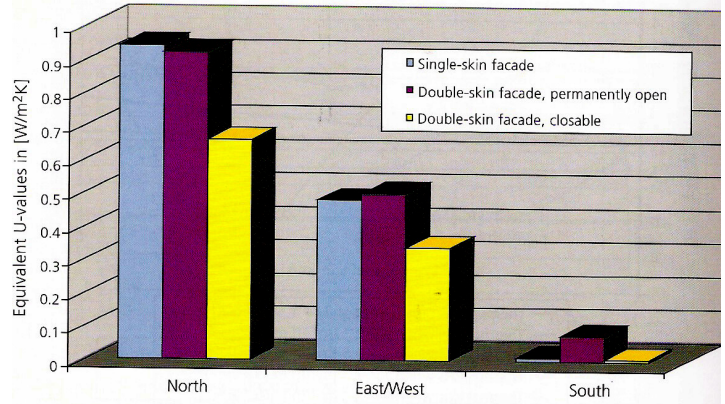

Figure 4: Equivalent U-value for different types of facades. Source: Oesterle et al [2].

The ventilated cavity space provides greater thermal insulation in both hot and cool climates. This could be accelerated by a ventilated sunshading system situated in the cavity. This system can have almost the same effect as an external installation, and will be much more efficient than internal shading behind solarcontrol glass (Oesterle et al [2]). The shades play an important role in absorbing heat and liberating it within the cavity. The absorbed heat is transmitted to the surrounding air and adjoining surface by means of radiation and convection. The position of the shading within the cavity plays a major role in the distribution of the heat gains. As pointed out by Oesterle et al [2], the optimal location of the shading is in the outer half of the cavity as shown in figure 3 . The air-tightness of the DSF also contributes to the qualities of thermal insulation. The improved Uvalue of the DSF depends mainly on the ventilation level of the intermediate space and the direction of the façade. Based on the analysis carried out by Oesterle et al [2], the U-value for a permanently ventilated intermediate space, in particular situations, is higher than that for a single-skin façade. However, the Uvalue for a closed cavity (with the provision of alternative mechanical ventilation) is usually lower (figure 4). 


\subsection{Daylight}

Daylight is one of the most important requirements for energy efficiency. In term of natural lighting, there is no big difference between DSF systems and singleskin types. DSFs with clear glazing layers can provide lots of daylight. On the other hand, they allow too much glare during the day and too much heat out during winter nights. The outer skin of DSFs can reduce the amount of daylight, depending on the construction type and the properties of the glass. The level of daylight admitted will also be reduced slightly if the glass thickness is increased.

\subsection{Sound control}

Blasco, in his study, has concluded that DSFs have an acoustical insulation that is far better (up to $10 \mathrm{~dB}$ ) than that of single-skin facades (Blasco et al [8]). The ventilation systems for the cavity and the inner spaces play an important role in sound transmission. On the other hand, the acoustical insulation between rooms depends on the differences in the ventilation strategy of the DSF (active, passive, and interactive types). Active types have internal mechanical ventilation with a high level of acoustical insulation. Passive types have natural ventilation of the cavity with a low level of acoustical insulation between rooms. Interactive types have natural ventilation with the aid of mechanical ventilator in the cavity. The degree of sound insulation provided by the DSF depends mainly on the size and position of the openings in the outer layer. Sound insulation can also be influenced by absorbent surfaces of the cavity (Oesterle et al [2]). In terms of sound control, the choice of the appropriate type of the DSF depends mainly not only on the site conditions such as traffic levels but also on the climate conditions.

\subsection{Cooling load reduction}

The construction of the DSF usually provides better solar protection that can reduce the effect of the external load and the cooling need. The additional layer of glazing can reduce the insulation by about 10 percent. Further reduction could be achieved by placing shading devices in the cavity space (Oesterle et al [2]). Reducing cooling load can be achieved by using a solar-control coating, reflective glazing, shading devices, and ventilated cavity space. With the construction of the DSF, the air-conditioning cost can be minimized. This could be achieved by providing for window ventilation, accelerated by using sunshadings placed in a ventilated cavity, induced by wind pressures and thermal buoyancy. Certainly, the glazing area and the glass type play an important role in reducing the cooling load. For instance, for DSF with a high proportion of glazing area, an appropriate glass with a low solar heat gain coefficient should be used to reduce solar loads. Low solar gain performance can also be achieved by reducing the glazing area while helping to reduce winter heat loss, glare, and uneven daylight (Straube and Straaten [7]). 


\subsection{Practical analysis: the use of DSF in Dubai}

Despite its advantages in terms of energy efficiency, the use of the DSF system is limited in Dubai. One of the main reasons is that the construction cost of such systems is high, compared with the construction cost of a single skin façade. To get a clear picture of the real financial incentives of using DSFs, a cost-benefit analysis study was carried out by the author in 2006 as part of individual funded research on "Thermal Performance of Double Skin Facades in Hot and Arid Climates" [9]. The methodology of the study was based on: 1) in-depth interviews with building designers and maintenance engineers, 2) simulation of single glazed façades, and 3) simulation of double skin facades. The study emphasized that the potential savings offered by the DSF strategy can overcome the high construction cost. Moreover, building performance and comfort can be maximized, especially for buildings situated in high traffic streets or close to airports. Renaissance Dubai Hotel was selected as a case study. It was built in 1992 and is situated in central Dubai, "Bar Dubai", near Dubai International Airport. The building is characterized by fully glazed facades. After comparative analysis of different building skins to coordinate mainly with the required sound control at that particular site, the highly energy efficient, and highly transparent facades, the architect decided on the strategy of DSFs, using the box-window system (figure 5). It incorporates an outer single glazed panel fastened to aluminium frames, inner double glazed operable windows with internal blinds controlled from inside to protect occupants from glare, and a $40 \mathrm{~cm}$ cavity between the two skins. The cavity is divided horizontally and vertically along the construction axes and between the individual windows. The horizontal platforms are covered by laminated sheets which act as horizontal sunshades and help to avoid the transmission of sounds and to control fire from spreading. It is recognized that the box-window type is commonly used in similar sites where there is high external noise level.

With a comparison with a conventional window, the U-value of the used boxwindow system was found to be in the order of $0.9 \mathrm{~W} / \mathrm{m}^{2}$. It has also been concluded from the study that this type of DSF has an acoustical façade insulation that is far better than that of conventional single glazed windows. The difference can reach up to $8 \mathrm{~dB}$ [9]. The airflow inside the cavity and the divisions between the outer and inner skins play an important role not only in thermal performance but also in sound control. The temperature of the inner skin is usually kept lower than it would be. This reduces the conduction, convection and radiation from the inner skin to the internal space. As a result, U-value is reduced, less energy (mainly for cooling) is required, visual transmittance is high, and acoustical insulation is provided.

The study concluded that the advantages of the DSF application depend mainly on the characteristics of the site, the function of the building, and the design of the façade and its integration with the inner spaces. At the early stages of the design process the following tasks should be included: 1) defining the function of the facade, concerning ventilation, thermal performance, sound control, daylight, and cooling and heating loads, 2) selecting the most 
appropriate type of DSF, and 3) optimizing the design of the air-conditioning system (Stec and Paassen [10]. In general, DSFs can provide different functional approaches, including: 1) sun protection and cooling load control, 2) improving thermal comfort and providing daylight, 3) enhancing natural ventilation schemes, 4) reducing operating costs by optimizing the daylight-thermal tradeoffs, and 5) improving indoor environments and enhancing occupant health, comfort, and performance (Selkowitz [1]).

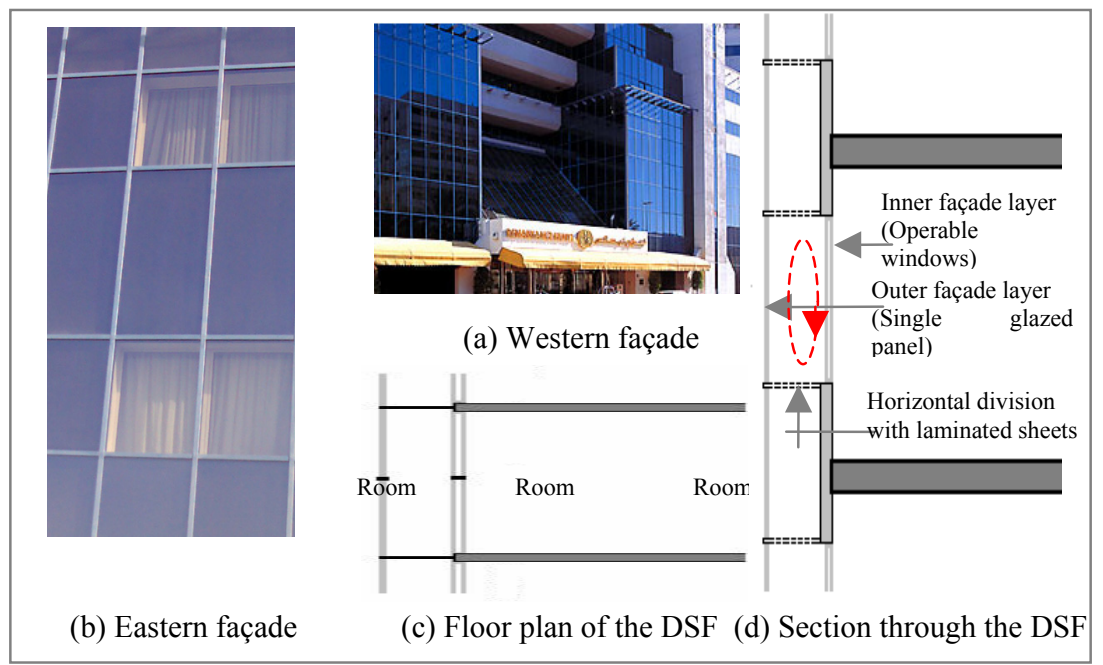

Figure 3: Renaissance Dubai Hotel [9].

Table 1: Performance characteristics of a DSF and best available glass walls. Source: Straube and Straaten [7].

\begin{tabular}{|l|c|c|c|c|}
\hline & $\begin{array}{c}\text { Solar Heat Gain } \\
\text { Coefficient }\end{array}$ & $\begin{array}{c}\text { Visual } \\
\text { transmittance }\end{array}$ & U-value & $\begin{array}{c}\text { Sound } \\
\mathrm{dB}\end{array}$ \\
\hline Opaque wall & $<0.02$ & 0.00 & $<0.35$ & $>45$ \\
\hline Double glazing & $0.28-0.40$ & $0.55-0.68$ & $1.1-1.4$ & $33-35$ \\
\hline Double glazing with exterior shades & $0.05-0.10$ & $0.55-0.68$ & $1.1-1.4$ & $33-35$ \\
\hline Double glazing with reflective coating & $0.07-0.20$ & $0.15-0.40$ & $1.4-1.5$ & $33-35$ \\
\hline Triple glazing with argon fill & $0.25-0.35$ & $0.52-0.62$ & $0.8-1.1$ & $38-45$ \\
\hline DSF - vented outer with shades & $0.10-0.30$ & $0.65-0.75$ & $1.0-1.5$ & $35-40$ \\
\hline DSF - exhaust vented with shades & $0.07-0.15$ & $0.70-0.75$ & $<0.70$ & $35-40$ \\
\hline
\end{tabular}

There have been many arguments about the energy efficiency of DSFs. Some of these arguments have proved that building with a DSF system uses 30 percent less energy than a similar building with a single-skin façade at the same site (Glicksman et al [4]). However, the performance of the façade is not isolated from other factors which may contribute to the efficiency of the building. The comparison analysis of the performance of various glazing technologies, which 
was carried out by Straube, concluded that the claim that DSFs are energy efficient is difficult to prove [7]. The result of this analysis, in terms of solar heat coefficient, visual transmittance, thermal transmission coefficient (U-value), and sound control is shown in Table 1. The solar heat gain coefficient for DSF systems with shading devices is between 0.07 and $0.30 \mathrm{~W} / \mathrm{m}^{2}$. This level of solar control can be achieved by a typical double glazing unit with reflective coatings, but at the cost of much lower visual transmittance, higher thermal transmission, and lower natural light transmission. On the other hand, the use of clear double glazing would result in a solar heat gain coefficient much higher than a DSF. However, the additional shadings to the exterior of a clear double glazing unit would allow for low heat gain values. Generally, DSF strategy is a good approach to overcome the large energy conservation and comfort problems that are created by the use of excessive glazing areas. Economically, there is an additional cost for the construction of DSFs compared with single skin façades. This additional cost has to be offset by lower costs achieved through greater functional efficiency.

\section{Conclusion}

The use of glazing facades has gained increasing popularity in Dubai. Architects and engineers seem to adopt the idea of transparent buildings more frequently, despite the fact that Dubai is one of the hottest cities in the Gulf region. This idea usually comes with a significant increase in operational costs due to the higher solar gain. To conquer such problems, there are several new design technique options, but one of the most advanced approaches is the use of double skin facades which introduces two or three glazing layers with a ventilated cavity between them. These techniques require extensive energy analysis and investigation in terms of natural ventilation, thermal performance, daylight performance, sound control, and cooling load reduction. Furthermore, there should be an economic justification for adopting such technology. The potential energy savings must be converted into real money in order to make real comparisons with the construction costs of building facades.

\section{References}

[1] Selkowitz, S., Integrating advanced facades into high performance building. Proc. of the $7^{\text {th }}$ International Glass Processing Day, Tampere, Finland, 2001.

[2] Oesterle et al, Double-Skin Facades, Prestel Verlag, London, 2001.

[3] Eaamar: www.eaamar.com

[4] Glicksman, L. et al, Double skin, airflow facades. Proc. of the International Conference on Building Envelope Systems and Technologies, Ottawa: Canada, Vol. 1, pp. 203-207, 2001.

[5] www.datadubai.com/technical-info

[6] Reid, E., Understanding Buildings: a Multidisciplinary Approach, Longman, London, 2001. 
[7] Straube, F. and R. Straaten, The Merit of Double Facades for Office Buildings in Cool Humid Climates, University of Waterloo, 2001.

[8] Blasco, M. et al, Acoustical performances of Double ventilated glass facades. Proc. of the $33^{\text {rd }}$ International Congress and Exposition on Noise Control Engineering, Prague, pp 1-10, 2004.

[9] Haggag, M. et al, Thermal Performance of Double Skin Facades in Hot and Arid Climates, Funded research, UAE University, 2005.

[10] Stec, W. and van Paassen, A., Double Skin Façade as a Part of the HVAC System. Report KK-322, TU Delft: Netherlands, 2002. 